\title{
Stereochemical trends of metal derivatives of some heterocyclic-2-thiones and thiosemicarbazones
}

\author{
TARLOK S LOBANA \\ Department of Chemistry, Guru Nanak Dev University, Amritsar 143 005, \\ India \\ e-mail: tarlok@angelfire.com
}

\begin{abstract}
The interaction of heterocyclic thiones/thiosemicarbazones with metals has been the subject of several investigations as these ligands contain chemically active groups, $-\mathrm{N}(\mathrm{H})-\mathrm{C}(=\mathrm{S})-\leftrightarrow-\mathrm{N}=\mathrm{C}(-\mathrm{SH})-$, and are useful model compounds for sulphur-containing analogues of purine and pyrimidine bases. Heterocylic-2-thiones bind to metals in several ways and lead to the formation of monomeric or polymeric complexes. For example, the simplest prototype of heterocylic-2-thiones, namely, pyridine-2-thione has several ways of binding, notably, terminal S-bonding and S-bridging (in neutral form), while in anionic form the modes are terminal S-bonding, S-bridging, N,S-chelation, N,S-bridging, N,S-chelation-cum-S-bridging and N,S-bridging-cum-S-bridging. Similarly, thiosemicarbazones bind to metals as $\mathrm{S}$-bonded unidentates or N,S-chelates. In this paper, the chemistry of pyridine-2thione, its N-oxide, 2-(benzylthio)pyridine-1-oxide thione with metals like iron(II), ruthenium(II), nickel(II), palladium(II), platinum(II), copper(I), copper(II), silver(I) and mercury(II) is briefly described. As regards thiosemicarbazones, focus is only on two compounds, namely organomercury(II) and organothallium(III). A variety of new molecules, well characterised by NMR and X-ray crystallography, is introduced.
\end{abstract}

Keywords. Heterocyclic thiones; thiosemicarbazones; tertiary phosphines; coordination properties; pyridine-2-thione; 1-hydroxy-pyridine-2-thione.

\section{Introduction}

The coordination chemistry of heterocyclic thiones containing $-\mathrm{N}(\mathrm{H})-\mathrm{C}(=\mathrm{S})-\leftrightarrow-\mathrm{N}=\mathrm{C}$ $(-\mathrm{SH})$ - functional group is of immense interest because such compounds (a) mimic cysteine sulphur coordination in metalloenzymes; (b) show electronic and structural properties of the active sites in copper blue proteins involving S,N-coordination and (c) comprise purine and pyrimidine bases. In addition, these and their $\mathrm{N}$-oxide derivatives have been found to have considerable biochemical properties. Similarly, thiosemicarbazones containing the $-\mathrm{N}=\mathrm{NH}-\mathrm{C}(=\mathrm{S})-\leftrightarrow=\mathrm{N}-\mathrm{N}=\mathrm{C}(-\mathrm{SH})$ - group are important ligands due to coordination with a variety of donor atoms and their numerous biochemical properties ${ }^{1-10}$.

In this paper, the coordination properties of pyridine-2-thione (HpyS, $\mathrm{C}_{5} \mathrm{H}_{5} \mathrm{NS}$ ), 1hydroxy-pyridine-2-thione (HpyOS, $\mathrm{C}_{5} \mathrm{H}_{5} \mathrm{NOS}$ ), 2-(benzylsulphanyl)-pyridine-1-oxide (pyOSBz) and a series of thiosemicarbazones with tertiary phosphines as co-ligands are described. The metals used for the synthesis of the compounds are $\mathrm{Fe}, \mathrm{Ru}, \mathrm{Ni}, \mathrm{Pd}, \mathrm{Pt}, \mathrm{Cu}$, $\mathrm{Ag}, \mathrm{Hg}$ and $\mathrm{Tl}$. 


\section{Heterocyclic thione derivatives of metals}

This section discusses details of work done with heterocyclic thiones mentioned in the introduction.The strategy here is to provide the main features of the work with all the attendant information available from the references. For convenience, the work is split into different groups.

\subsection{Iron and ruthenium}

In the case of iron, though several reactions were carried out, not much could be established. Reaction of anhydrous $\mathrm{FeCl}_{3}$ with $\mathrm{HpyS}$ in ethanol followed by the addition of a tertiary phosphine was carried out to prepare an octahedral complex $\mathrm{FeCl}_{2}$ (pyS$\mathrm{N}, \mathrm{S})\left(\mathrm{PPh}_{3}\right)_{2}$. However, the product turned out to be $\mathrm{FeCl}_{2}(\mathrm{HpyS})_{2}(\mathbf{1})$ whose X-ray study established tetrahedral structure with HpyS binding to $\mathrm{Fe}(\mathrm{II})$ via $\mathrm{S}$ donor atom and the free $\mathrm{NH}$ group forming an intermolecular hydrogen bond with $\mathrm{Cl}$ atoms of adjacent molecules ${ }^{11}$. There was the expected oxidation of HpyS to pySSpy, but the same was not established. Later on, another group ${ }^{12}$ carried out the reaction of $\mathrm{FeCl}_{3}$ with $\mathrm{HpyS}$ in ethanol at room temperature and isolated the product $[\mathrm{pySSpyH}]^{+}\left[\mathrm{FeCl}_{4}\right]^{-}$. Due to the complex behaviour of iron in these systems, our efforts to synthesize several mixed ligand complexes of the type $\mathrm{FeX}_{2}$ (pyS-N, S) (diphosphine) $(\mathrm{X}=\mathrm{Cl}, \mathrm{Br}, \mathrm{I})$, with HpyOS ditertiary phosphine were not successful.

In contrast, ruthenium(II) showed the expected behaviour. The reaction of $\mathrm{Ru}\left(\mathrm{PPh}_{3}\right)_{3} \mathrm{Cl}_{2}$ with HpyS (1:2 ratio) in benzene or toluene in presence of triethylamine formed $\mathrm{Ru}(\text { pyS-N,S })_{2}\left(\mathrm{PPh}_{3}\right)_{2}(\mathbf{2})$, which has a distorted (cis, cis, trans : : N,N; P,P; S,S) octahedral structure ${ }^{13}$. Similar reaction of $\mathrm{Ru}(\mathrm{dppe})_{2} \mathrm{Cl}_{2} \quad$ dppe $\left.=\mathrm{Ph}_{2} \mathrm{P}-\left(\mathrm{CH}_{2}\right)_{2}-\mathrm{PPh}_{2}\right\}$ with HpyS in presence of $\mathrm{Et}_{3} \mathrm{~N}$ in benzene did not form Ru(pyS-N,S)$)_{2}($ dppe) (3), instead crystals of $\mathrm{Ru}(\mathrm{dppe})_{2} \mathrm{Cl}_{2}$ were formed having trans-octahedral structure with chelating dppe ${ }^{14} .3$ was then prepared by replacing $\mathrm{PPh}_{3}$ from 2 by dppe in benzene as solvent ${ }^{15}$. Reaction of 2 with a tritertiary phosphine $\left\{\mathrm{Ph}_{2} \mathrm{P}-\mathrm{CH}_{2}-\mathrm{CH}_{2}\right\}_{2} \mathrm{P}(\mathrm{Ph})$ (triphos) also formed $\mathrm{Ru}(\text { pyS }-\mathrm{N}, \mathrm{S})_{2}$ (triphos- $\left.\mathrm{P}, \mathrm{P}\right)$ (4) with one pendant $\mathrm{Ph}_{2} \mathrm{P}$-group. The compounds with dppm, dppp and dppb $\left\{\mathrm{Ph}_{2} \mathrm{P}-\left(\mathrm{CH}_{2}\right)_{m}-\mathrm{PPh}_{2}, m=1\right.$, dppm, $m=3$, dppp and $m=4$, dppb $\}$, as well as derivatives of HpyOS were prepared by the method used for $\mathbf{2}^{15}$. The X-ray structures of $\mathrm{Ru}(\mathrm{pyS})_{2}(\mathrm{~L}-\mathrm{L})\left\{\mathrm{L}-\mathrm{L}=\right.$ dppe, $\mathbf{3}^{16}$, dppp, $\mathbf{5}^{17}$ and dppb, $\mathbf{6}^{18}$, also showed structures similar to that of 2 . The trans-S-Ru-S bond angles are similar, 154.7-155.9. however, cis- $\mathrm{P}-\mathrm{Ru}-\mathrm{P}$ and cis $-\mathrm{N}-\mathrm{Ru}-\mathrm{N}$ bond angles vary in the order, $\mathrm{N}-\mathrm{Ru}-\mathrm{N}$, $m=$ dppe $>$ dppp $>$ dppb and $\mathrm{P}-\mathrm{Ru}-\mathrm{P}$ and $m=\mathrm{dppb}>\mathrm{dppp}>\mathrm{dppe}$. Thus shorter the chain length connecting $\mathrm{Ph}_{2} \mathrm{P}$-groups, larger the $\mathrm{N}-\mathrm{Ru}-\mathrm{N}$ bond angle \{PRuP angles are in

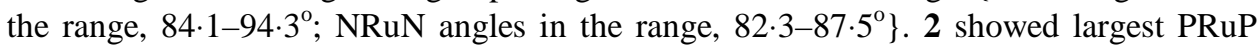
and shortest NRuN angles $\left\{96 \cdot 8^{\circ}, 80 \cdot 9^{\circ}\right.$ respectively $\}$. High resolution ${ }^{13} \mathrm{C}$ NMR study of 5 showed that $\mathrm{Ph}$ groups on $\mathrm{P}$ are non-equivalent as two sets of triplets for $i, o, m$ carbons were found ${ }^{17}$. The magnetic non-equivalence of $\mathrm{Ph}$ groups is due to the relative orientation of the pyridyl group to one of the $\mathrm{Ph}$ groups of the $\mathrm{Ph}_{2} \mathrm{P}$ moiety. Further, complexes were found to undergo one-electron redox reactions as shown by cyclic voltammetric studies ${ }^{15}$.

\subsection{Nickel, palladium and platinum}

2.2a Nickel(II): Only a few nickel compounds have been studied due to lack of interaction of $\mathrm{Ni}$ (pyOS) $)_{2}$ \{obtained from $\mathrm{NiCl}_{2} \cdot 6 \mathrm{H}_{2} \mathrm{O}$ and $\mathrm{Na}^{+}$pyOS${ }^{-}$\} moiety with 
tertiary phosphines - this being of interest to us in the study in mixed-ligand complexes containing heterocyclic thiones and tertiary phosphines ${ }^{19}$. Thus a few compounds with 2,2'-pyridyl (bipy) and 1,10-phenanthroline (phen) have been reported. Reaction of $\mathrm{Ni}(\text { pyOS })_{2}$ with bipy in chloroform formed two isomers, 7 (parrot-green) and $\mathbf{8}$ (yellowbrown). While the former is diamagnetic (major) the latter is paramagnetic (minor) ${ }^{19}$. The diamagnetic is believed to be having $\mathrm{NiN}_{2} \mathrm{~S}_{2}$ atoms in the square planar geometry of 7 with the $\mathrm{O}$ atoms having weak or no interaction along the $z$-axis. $\mathrm{Ni}(\text { pyOS })_{2}$ (phen) (9) was prepared by the same method and showed no isomers like bipy compounds. 8 and 9 showed intermediate magnetic moment values with $m=2.55 \mathrm{BM}$.

2.2b Palladium(II) and platinum(II): Palladium(II) acetate with HpyS forms $\mathrm{N}, \mathrm{S}$ bridged dimer $\left\{\mathrm{Pd}_{2}(\mathrm{pyS}-\mathrm{N}, \mathrm{S})_{4}\right\}(\mathbf{1 0})^{20}$ and the same can be prepared from $\mathrm{PdCl}_{2}$ and $\mathrm{Na}^{+}$pyS ${ }^{-}$in $\mathrm{CH}_{3} \mathrm{CN}$ solvent ${ }^{21}$. Reaction of $\mathbf{1 0}$ with $\mathrm{PPh}_{3}$ in $1: 2$ mole ratio formed $\mathrm{Pd}(\mathrm{pyS}-$ $\mathrm{S})_{2}\left(\mathrm{PPh}_{3}\right)_{2}(11)$ having trans-square planar geometry ${ }^{21}$ which was proposed on the basis of ${ }^{1} \mathrm{H}$ and ${ }^{13} \mathrm{C}$ NMR data and X-ray structure of an analogous Pt complex 12 (vide infra). Similarly, reaction of N,S-bridged dimer $\mathrm{Pt}_{2}(\text { pyS-N,S })_{4}$ \{ obtained from $\mathrm{PtCl}_{2}$ and $\mathrm{Na}^{+}$pyS ${ }^{-}$in $\left.\mathrm{CH}_{3} \mathrm{CN}\right\}$ with $\mathrm{PPh}_{3}$ in 1:2 $\left(\mathrm{Pt}_{\mathrm{PPh}}\right)$ mole ratio formed monomeric $\mathrm{Pt}(\mathrm{pyS}-$ $\mathrm{S})_{2}\left(\mathrm{PPh}_{3}\right)_{2} 12$ having $\mathrm{S}$-bonded pyridine-2-thionate groups in trans orientation as established by X-ray crystallography ${ }^{22} .12$ was found to dissociate in $\mathrm{CHCl}_{3}$ solution as shown by ${ }^{31} \mathrm{P}$ NMR spectroscopy,

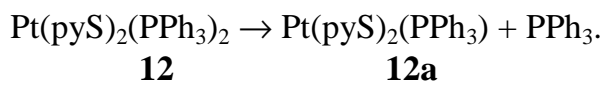

12a was shown to have both $\mathrm{N}, \mathrm{S}$-chelated and S-bonded pyS moieties by ${ }^{13} \mathrm{C} \mathrm{NMR}$ spectroscopy ${ }^{22}$. Other tertiary phosphine derivatives structurally established are Pd(pyS$\mathrm{N}, \mathrm{S}) \mathrm{Cl}\left(\mathrm{PPh}_{3}\right)^{23}$ and $\left[\mathrm{Pt}(\mathrm{pyS}-\mathrm{N}, \mathrm{S})\left(\mathrm{PPh}_{3}\right)_{2}\right]^{+}\left(\mathrm{PF}_{6}\right)^{-24}$.

The use of diphosphines in place of $\mathrm{PPh}_{3}$ also gave interesting results. From $\mathrm{PtCl}_{4}$, HpyS and dppe or dppen in presence of $\mathrm{Et}_{3} \mathrm{~N}$ in the solvent benzene, the compounds, $\left[\mathrm{Pt}(\mathrm{pyS}-\mathrm{S})_{2}(\mathrm{~L}-\mathrm{L})\right] \quad\left\{\mathrm{L}-\mathrm{L}=\right.$ dppe, 13, dppen $\left.\left(\mathrm{Ph}_{2} \mathrm{PCH}=\mathrm{CHPPh}\right)_{2}, \mathbf{1 4}\right\}$ were formed containing chelating diphosphines and S-bonded pyS groups with pendant pyridyl groups ${ }^{25}$ which are confirmed by ${ }^{13} \mathrm{C}$ NMR and X-ray crystallography. A similar product, $\left[\mathrm{Pd}(\mathrm{pyS}-\mathrm{S})_{2}(\mathrm{~L}-\mathrm{L})\right]\{\mathrm{L}-\mathrm{L}=\mathrm{dppe}, 15\}$ was formed from $\left[\mathrm{PdCl}_{2}(\mathrm{dppe})\right]$ and $\mathrm{HpyS}$ in presence of sodium hydroxide ${ }^{25}$. All three have been established with X-ray crystallography and represent the first examples of $\mathrm{Pt}^{\mathrm{II}} / \mathrm{Pd}^{\mathrm{II}}$ complexes containing cis pendant pyridyl groups which may act as precursors for polymeric complexes. The ${ }^{31} \mathrm{P}$ NMR spectra of 14 showed ${ }^{31} \mathrm{P}$ signals with a pair of satellites due to coupling from ${ }^{195} \mathrm{Pt}$ $(I=1 / 2)$ while 13 showed one ${ }^{31} \mathrm{P}$ signal with a pair of satellites. The presence of two sets of ${ }^{31} \mathrm{P}$ signals could be due to the non-equivalent pyridyl groups opposite the $\mathrm{P}$ atoms and this non-equivalence is probably not resolved in case of the dppe complex $\mathbf{1 3}$. While the $J_{\mathrm{P}-\mathrm{Pt}}$ constants are similar in magnitude in the two cases $\left[\mathbf{1 3}, J_{\mathrm{P}-\mathrm{Pt}}, 2968 \cdot 2 \mathrm{~Hz}, \mathbf{1 4}, J_{\mathrm{P}-\mathrm{Pt}}\right.$, $2958.5,2969.4 \mathrm{~Hz}$ ), the coordination shifts are different $[\mathbf{1 3}, \Delta \mathrm{dP} 58.2, \mathbf{1 4}, \Delta \mathrm{dP}$ $77 \cdot 1 \mathrm{ppm}]$. Thus dppen was found to coordinate more strongly to the Pt centre than dppe. The difference is attributed to the unsaturation in the $-\mathrm{CH}=\mathrm{CH}-$ moiety of dppen which could favour increased charge delocalisation in the Pt-dppen moiety. With other diphosphines and phosphine chalcogenides similar products have been prepared ${ }^{25}$.

The HpyOS derivatives of $\mathrm{Pd} / \mathrm{Pt}$ of the type $\mathrm{M}(\mathrm{pyOS}-\mathrm{O}, \mathrm{S})_{2}$ showed poor tendency to form tertiary phosphine complexes and none could be established from X-ray 
crystallography ${ }^{21}$. It is interesting to point out that whereas $\mathrm{Pd}(\mathrm{pyOS}-\mathrm{O}, \mathrm{S})_{2}$ showed only one species having $c i s$-sulphur atoms, NMR showed two isomers for $\mathrm{Pt}(\mathrm{pyOS})_{2}$ having cis- and trans-isomers with respect to O,S-donor atoms ${ }^{21}$.

\subsection{Copper}

Reaction of $\mathrm{CuCl}_{2} \cdot 2 \mathrm{H}_{2} \mathrm{O}$ with $\mathrm{HpyS}$ in ethanol forms an insoluble ESR inactive material of composition $\mathrm{CuCl}\left(\mathrm{HpyS}\right.$ ) which on reaction with two equivalents of $\mathrm{Ph}_{3} \mathrm{P}$ in $\mathrm{CHCl}_{3}$ formed the product $\left[\mathrm{CuCl}(\mathrm{HpyS}-\mathrm{S})\left(\mathrm{PPh}_{3}\right)_{2}\right]$, 16. Similarly, with ditertiary phosphines, the compounds, $[\mathrm{CuCl}(\mathrm{HpyS}-\mathrm{S})(\mathrm{L}-\mathrm{L})]\{\mathrm{L}-\mathrm{L}=\mathrm{dppm}$, dppe, dppp and dppb $\}$ were formed and the behaviour of copper(II) bromide salt was identical ${ }^{26,27}$. X-ray crystallography of $\mathbf{1 6}$ established tetrahedral structure with $\mathrm{NH}$......Cl intramolecular hydrogen bonding ${ }^{27}$. It was interesting to know that there was no reaction with $\mathrm{Ph}_{3} \mathrm{PO}$, $\mathrm{Ph}_{3} \mathrm{PS}, \mathrm{Ph}_{3} \mathrm{PSe}$ and $\mathrm{Ph}_{3} \mathrm{As}$ and this supports the fact that tertiary phosphines are strong Lewis bases vis-a-vis phosphine chalcogenides or arsines, as mentioned above ${ }^{26}$. In the case of HpyOS, similar reactions formed $\mathrm{Cu}^{\mathrm{II}}$ complexes, $\mathrm{CuX}($ pyOS-O,S $)\left(\mathrm{L}_{2}\right)$ or $\mathrm{CuX}($ pyOS-O,S $)(\mathrm{L}-\mathrm{L})\left\{\mathrm{L}=\mathrm{Ph}_{3} \mathrm{P}\right.$ and $\mathrm{L}-\mathrm{L}=$ diphosphines as mentioned above $\}$ which were ESR active (here HpyOS behaved as an anionic ligand). However, none could be crystallised to establish molecular structure ${ }^{28}$. Unlike $\mathrm{Ph}_{3} \mathrm{P}$ or diphosphines, the substituted tertiary phosphines namely tri- $p$-tolyl $\left(p-\mathrm{Tol}_{3} \mathrm{P}\right)$ and tri-meta-tolyl phosphines $\left(m-\mathrm{Tol}_{3} \mathrm{P}\right)$ with copper(I) halides and HpyS formed 1:1:1 complexes of the type $\left[\mathrm{CuX}(\mathrm{HpyS}-\mathrm{S})\left(\mathrm{PR}_{3}\right)\right](\mathrm{X}=\mathrm{Cl}, \mathrm{Br}, \mathrm{I})$ which were established to be dimeric using $\mathrm{X}$-ray crystallography ${ }^{29}$. The dimer formation occurs via $\mathrm{S}$ donor atoms. Weak $\mathrm{Cu}$....Cu or S...S interactions were noticed in the central moiety $\mathrm{Cu}_{2} \mathrm{~S}_{2}$ with $\mathrm{R}_{3} \mathrm{P}$ and $\mathrm{X}$ groups in transposition and the free-end $\mathrm{NH}$ of HpyS having $\mathrm{NH}$...X intra-molecular hydrogen bonding. Interestingly for $\mathrm{X}=\mathrm{Br}$ and $\mathrm{R}_{3} \mathrm{P}=\mathrm{Ph}_{3} \mathrm{P}$, both $1: 1$ and $1: 2$ products were established ${ }^{30}$. For the dimeric complexes, ${ }^{31} \mathrm{P}$ NMR showed dissociation as follows

$$
\begin{aligned}
{[\mathrm{CuX}(\mathrm{HpyS}) \mathrm{L}]_{2} \leftrightarrow } & \mathrm{Cu}_{2} \mathrm{X}_{2}(\mathrm{HpyS})_{2} \mathrm{~L}+\mathrm{L}, \\
& \left(\mathrm{X}=\mathrm{Cl}, \mathrm{Br}, \mathrm{I} ; \mathrm{L}=m-\mathrm{Tol}_{3} \mathrm{P}, p-\mathrm{Tol}_{3} \mathrm{P}\right) .
\end{aligned}
$$

Like Ni(II), copper(II) formed only one adduct with phen in chloroform having stoichiometry, $\mathrm{Cu}$ (pyOS) $)_{2}$ (phen). $3 / 4 \mathrm{CHCl}_{3}(\mathbf{1 7})$ and conductance showed the product to have the formulate as, $\left[\mathrm{Cu}(\right.$ pyOS $\left.)(\text { phen })_{2}\right]\left[\mathrm{Cu}(\text { pyOS })_{3}\right] 1 \cdot 5 \mathrm{CHCl}_{3}{ }^{19} .17$ is ESR active and the spectrum is commensurate with an elongated structure.

\subsection{Silver and mercury}

Silver(I) complexes, $\operatorname{Ag}($ pyOS $)-\mathrm{O}, \mathrm{S})(\mathrm{L})\left[\mathrm{L}=\mathrm{dppm}, \mathbf{1 8}, \mathrm{dppb}, \mathrm{PPh}_{3}\right.$, and $\left.m-\mathrm{Tol}_{3} \mathrm{P}\right]$ were obtained from silver(I) acetate and neutral HpyOS in water-ethanol medium followed by addition of tertiary phosphines. Direct reaction of mercury(II) halides with 2(benzylthio)pyridine-1-oxide (pyOSBz-O) in ethanol formed $\mathrm{HgX}_{2}(\mathrm{pyOSBz})[\mathrm{X}=\mathrm{Cl}$, 19, Br]. Similarly, organomercury(II) derivatives, $\mathrm{RHgL}\left[\mathrm{R}=m-\mathrm{NO}_{2} \mathrm{C}_{6} \mathrm{H}_{4^{-}}, \mathrm{L}=\mathrm{pyS} \mathrm{S}^{-}\right.$, pyOS $; \mathrm{R}=p-\mathrm{ClC}_{6} \mathrm{H}_{4^{-}}, \mathrm{L}=$ pyS $^{-}$, pyOS $^{-} ; \mathrm{R}=\mathrm{C}_{6} \mathrm{H}_{5^{-}}, \mathrm{L}=$ pyS $^{-}, \mathbf{2 0}$, pyOS $\left.{ }^{-}\right]$were prepared from $\mathrm{Hg}(\mathrm{R})\left(\mathrm{OOCCH}_{3}\right)$ and neutral pyridine-2-thiones HpyS or HpyOS). 18 exists as a dimer with dppm bridging the two Ag atoms leading to the formation of an eightmembered metallacyclic ring with pyOS moieties chelating to each $\mathrm{Ag}$ atom via $\mathrm{O}, \mathrm{S}$ donor atoms. The geometry about each $\mathrm{Ag}$ centre is a highly distorted tetrahedral with 
bond angles varying from $72 \cdot 85(7)^{\circ}$ to $137.92(4)^{\circ}$. Compounds $\mathbf{1 9}$ and $\mathbf{2 0}$ acquire formally dimeric structures via weaker interactions. For example in $\mathbf{1 9}, \mathrm{Hg}$ binds strongly to one $\mathrm{O}$ atom and two $\mathrm{Cl}$ atoms, and weakly to one $\mathrm{Cl}$ atom and one $\mathrm{S}$ atom of the second molecule. The geometry about each $\mathrm{Hg}$ atom is formally highly distorted trigonal bipyramidal with $\mathrm{Cl}(1)-\mathrm{Hg}-\mathrm{Cl}(2)$ and $\mathrm{O}(1)-\mathrm{Hg}-\mathrm{S}(1) *$ bond angles of $172 \cdot 84(5)$ and $151.70(9)^{\mathrm{o}}$ respectively. Finally in $\mathbf{2 0}, \mathrm{Hg}$ is bonded strongly to one $\mathrm{C}$ and one $\mathrm{S}$ atom, relatively weakly to $\mathrm{N}\{\mathrm{Hg}-\mathrm{N}, 2 \cdot 795(10), 2 \cdot 879(9) \AA\}$ and very weakly to the second $\mathrm{S}$ atom of the second molecule $\{\mathrm{Hg}-\mathrm{S}, 3 \cdot 312(3), 3 \cdot 365(3) \AA$ A $\}$. If secondary interactions are ignored, the geometry about the $\mathrm{Hg}$ atom is formally distorted T-shaped ${ }^{31}$. The tricoordinate complex $\left\{\mathrm{Ag}(\right.$ pyOS-O,S $\left.)\left(\mathrm{PPh}_{3}\right)\right\}$ is also dimeric with the $\mathrm{Ag}_{2} \mathrm{~S}_{2}$ central moiety, terminal $\mathrm{PPh}_{3}$ molecules and chelating pyOS ${ }^{-}$groups ${ }^{32}$ dimerising via $\mathrm{S}$-atoms.

\section{Thiosemicarbazone derivatives of metals}

\subsection{Mercury}

The reactions of phenylmercury(II) acetate with a series of thiosemicarbazones in ethanol medium at room temperature formed novel phenylmercury(II) thiosemicarbazonates of stoichiometry $[\mathrm{HgPh}(\mathrm{L})] \quad\left\{\mathrm{HL}: \mathrm{R}=\mathrm{N}^{3}-\mathrm{N}^{2} \mathrm{H}-\mathrm{C}^{1}(\mathrm{~S})-\mathrm{N}^{1} \mathrm{H}_{2}, \quad\right.$ cyclopentanone $\quad$ (21), cyclohexanone (22), benzaldehyde (23), 4-methoxybenzaldehyde (24), pyrrole-2carbaldehyde (25), thiophene-2-carbaldehyde (26) and furan-2-carbaldehyde (27) thiosemicarbazones ${ }^{33}$. The ${ }^{1} \mathrm{H}$ and ${ }^{13} \mathrm{C}$ NMR data suggest that the thiosemicarbazones deprotonate the most acidic hydrazinic $\mathrm{N}^{2} \mathrm{H}$ proton during reaction with phenylmercury(II) acetate and coordinate to $\mathrm{Hg}$ (II) via chelating $\mathrm{N}^{3}$,S-donor atoms. ${ }^{199} \mathrm{Hg}$ NMR data suggest symmetrisation phenomenon as below for complexes $\mathbf{2 3}$ and $\mathbf{2 4}$, which is supported by ${ }^{1} \mathrm{H}$ and ${ }^{13} \mathrm{C}$ NMR data.

$$
2[\mathrm{HgPhL}] \rightleftarrows \mathrm{HgPh}_{2}+\mathrm{HgL}_{2} .
$$

Mercury chemical shift values reveal that shielding of $\mathrm{Hg}$ with the change of organic groups in the thiosemicarbazones decreases in the order: 2-hydroxybenzene >> furan $>$ benzene $>4$-methoxybenzene $>>$ thiophene $\approx$ cyclohexanone $\approx$ cyclopentanone $>$ pyrrole while the Lewis acidity of the thiosemicarbazones varies in the reverse order. The ${ }^{1} \mathrm{H}$ and ${ }^{13} \mathrm{C}$ NMR data reveal that 26 and 27 show isomerism. The weak intermolecular interactions via $\mathrm{Hg} \ldots . . \mathrm{N}^{2}$ in $\mathbf{2 1}$ and via $\mathrm{Hg} \ldots \mathrm{S}$ in $\mathbf{2 4}$ and $\mathbf{2 5}$ form centrosymmetric dimers and $\mathrm{Hg}$ formally acquires four coordination with two strong $(\mathrm{Hg}-\mathrm{C}, \mathrm{Hg}-\mathrm{S})$, one weak $\left(\mathrm{Hg} \ldots . . . \mathrm{N}^{3}\right)$ and one secondary $\left(\mathrm{Hg} \ldots . . . \mathrm{N}^{2}\right.$ or S) bonds. The preferred dimer formation via $\mathrm{N}^{2}$ nitrogen in $\mathbf{2 1}$, rather than via sulphur atoms $(\mathbf{2 4}$ and 25) despite $\mathrm{Hg}$....S affinity, represents an unusual bonding mode. The low temperature studies show that the energy barrier to rotation of $\mathrm{N}^{1} \mathrm{H}$ group about $\mathrm{C}^{1}-\mathrm{N}^{1}$ bond varies in the order $\mathbf{2 4}>\mathbf{2 5} \sim \mathbf{2 1}>\mathbf{2 2}$.

It may be interesting to know that whereas acetophenone thiosemicarbazone $\left(\mathrm{R}=\mathrm{N}^{3}\right.$ $\mathrm{N}^{2} \mathrm{H}-\mathrm{C}^{1}(\mathrm{~S})-\mathrm{N}^{1} \mathrm{H}_{2}, \mathrm{R}=$ acetophenone $)$ reaction with $\mathrm{PhHg}(\mathrm{OAc})$ forms black material, the same reaction with $\mathrm{PhHgCl}$ leads to symmetrisation phenomenon as noted in some complexes mentioned above ${ }^{34}$ :

$$
2 \mathrm{PhHgCl}+\mathrm{L} \rightarrow \mathrm{Ph}_{2} \mathrm{Hg}+\mathrm{HgCl}_{2} \mathrm{~L}_{2} .
$$




\subsection{Thallium(III)}

The reactions of diphenylthallium(III) hydroxide with a series of thiosemicarbazones in water-ethanol medium at room temperature formed novel diphenylthallium(III) thiosemicarbazonates of stoichiometry $\left[\mathrm{TlPh}_{2}(\mathrm{~L})\right] \quad\left\{\mathrm{HL}: \mathrm{R}=\mathrm{N}^{3}-\mathrm{N}^{2} \mathrm{H}-\mathrm{C}^{1}(\mathrm{~S})-\mathrm{N}^{1} \mathrm{H}_{2}\right.$, cyclopentanone (28), benzaldehyde (29), 2-hydoxybenzaldehyde (30), 4methoxybenzaldehyde (31), acetophenone (32), furan-2-carbaldehyde (33), pyridine-2formaldehyde (34), and pyridine-2-acetaldehyde thiosemicarbazones $(\mathbf{3 5})\}{ }^{35}$. $\mathrm{H}$ and ${ }^{13} \mathrm{C}$ NMR data suggest that the thiosemicarbazones deprotonate the most acidic hydrazinic $\mathrm{N}^{2} \mathrm{H}$ proton during reaction with $\mathrm{TlPh}_{2}(\mathrm{OH})$ and coordinate to $\mathrm{Tl}(\mathrm{III})$ via chelating $\mathrm{N}^{3}, \mathrm{~S}$ donor atoms (28-33) or chelating $\mathrm{N}^{4}, \mathrm{~N}^{3}, \mathrm{~S}$-donor atoms (34 and 35). In all the cases, thiosemicarbazones change the conformation from E-mode to Z-mode. ${ }^{205} \mathrm{Tl}$ NMR suggest more than one species involving intra- or inter-molecular interactions for 28-33 and only one species for $\mathbf{3 4}$ and $\mathbf{3 5}$. Thallium chemical shift values reveal that the shielding of $\mathrm{Tl}$ with the change of organic group in the thiosemicarbazones decreases in the order, 2-formyl-pyridine > 2-acetyl-pyridine $>2$-hydroxybenzene $>$ benzene $>$ 4-methoxy-benzene > furan > 2-acetyl-benzene > cyclopentanone. In $\mathbf{2 8}, \quad \mathrm{Tl}(\mathrm{III})$ is bonded to two carbon atoms of phenyl group [Tl-C, 2.146(6), 2.148(6) $\mathrm{A}], \mathrm{N}^{3}$ and $\mathrm{S}$ atoms $\left[\mathrm{Tl}-\mathrm{N}^{3}, \quad 2 \cdot 55(1) \AA\right.$; $\left.\quad \mathrm{Tl}-\mathrm{S}, \quad 2 \cdot 616(3) \AA\right]$ of deprotonated cyclopentanone thiosemicarbazones (Hcptsc). The $\mathrm{C}^{7}-\mathrm{Tl}-\mathrm{C}^{13}$ and $\mathrm{N}^{3}-\mathrm{Tl}-\mathrm{S}$ bond angles of 146.6(2) and $72.90(12)^{\circ}$ suggest a distorted trigonal bipyramid geometry with one vacant site in the equatorial plane. $\mathbf{3 4}$ and $\mathbf{3 5}$ exist as 3 -independent molecules each with distorted trigonal bipyramid geometry. $\mathrm{Tl}$ is coordinated to two carbon atoms and $\mathrm{N}^{3}, \mathrm{~N}^{4}$ and $\mathrm{S}$ atoms of deprotonated pytsc and acpytsc anions. The bond lengths and angles of 3-independent molecules of both $\mathbf{3 4}$ and $\mathbf{3 5}$ are different though similar to those for $\mathbf{2 8}$. The existence of 3 -independent molecules in the lattice represents novel and unusual examples in organothallium(III) chemistry. The low temperature proton NMR studies of $\mathbf{3 4}$ and $\mathbf{3 5}$ reveal that the energy barrier to rotation of the amino groups about $\mathrm{C}^{1}-\mathrm{N}^{1}$ bond is a bit higher than that in analogous $\mathrm{PhHg}$ (II) systems.

\section{Acknowledgements}

The author thanks Guru Nanak Dev University, Amritsar, University Grants Commission, New Delhi, Department of Atomic Energy, Mumbai and the Government of Spain for financial support.

\section{References}

1. Raper E S 1985 Coord. Chem. Rev. 61115

2. Raper E S 1996 Coord. Chem. Rev. 153199

3. Campbell M J M 1975 Coord. Chem. Rev. 15279

4. Padhye S B and Kauffman G B 1985 Coord. Chem. Rev. 63127

5. West D X, Padhye S B and Sonawane P B 1991 Struct. Bonding (Berlin) 764

6. West D X, Liberta A E, Padhye S B, Chilate R C, Sonawane P B, Kumbhar A S and Yerande R G 1993 Coord. Chem. Rev. 12349

7. Lobana T S and Bhatia P K 1989 J. Sci. Ind. Res. 48394

8. Rodriguez-Arguelles M C, Ferrari M B, Fava G G, Pelizzi G, Tarasconi P, Albertini R, Dall'Aglio P P, Lunghi P and Pinelli S 1995 J. Inorg. Biochem. 58157

9. Casas J S, Garcia-Tasende M S, Maichle-Mossmer C, Rodriguez-Arguelles M C, Sanchez A, Sordo J, Vazquez-Lopez A, Pinelli S, Lunghi P and Albertini R 1996 J. Inorg. Biochem. 6241 
10. Ferrari M B, Fava G G, Tarasconi G, Albertini R, Pinelli S and Starcich R 1994 J. Inorg. Biochem. 5313

11. Povey D C, Smith G W, Lobana T S and Bhatia P K 1991 J. Crystallogr. Spectrosc. Res. 219

12. Couce M D, Russo U and Valle G 1995 Inorg. Chim. Acta 234195

13. Fletcher S R and Skapski A C 1972 J. Chem. Soc., Dalton Trans. 635

14. Lobana T S, Singh R and Tiekink E R T 1990 J. Coord. Chem. 21225

15. Lobana T S and Singh R 1995 Polyhedron 14907

16. Tiekink E R T, Lobana T S and Singh R 1991 J. Crystallogr. Spectrosc. Res. 21205

17. Lobana T S, Verma R, Singh R and Castineiras A 1998 Transition Met. Chem. 2325

18. Horn E, Lobana T S, Singh R and Tiekink E R T 1993 Z. Kristallogr. 205291

19. Lobana T S and Paul S 1996 Transition Met. Chem. 21300

20. Rosenfield S G, Berends H P, Gelmini L, Stephen D W and Masacharak P K 1987 Inorg. Chem. 262792

21. Lobana T S and Verma R 1999 Indian J. Chem. Sect. A 38592

22. Lobana T S, Verma R and Castineiras A 1998 Polyhedron 173753

23. Nakatsu Y, Nakamura Y, Matsumoto K and Ooi S 1992 Inorg. Chim. Acta 19681

24. Wang S, Staples R J and Fackler J P Jr 1994 Acta Crystallogr. C50 889

25. Lobana T S, Verma R, Hundal G and Castineiras A 1999 Polyhedron (in press)

26. Lobana T S and Bhatia P K 1990 Indian J. Chem. A29 1225

27. Lobana T S, Bhatia P K and Tiekink E R T 1989 J. Chem. Soc., Dalton Trans. 749

28. Lobana T S and Bhatia P K 1992 J. Chem. Soc., Dalton Trans. 1407

29. Lobana T S, Paul S and Castineiras A 1997 Polyhedron 164023

30. Karagiannidis P, Aslandis P, Kessissoglou D P, Krebs D and Dartmann M 1989 Inorg. Chim. Acta 15647

31. Lobana T S, Paul S and Castineiras A 1999 J. Chem. Soc., Dalton Trans. 1819

32. Lobana T S, Paul S, Hundal G and Obrai S 1999 Transition Met. Chem. 24202

33. Lobana T S, Sanchez A, Casas J S, Castineiras A, Sordo J, Garcia-Tasende M S and VazquezLopez E M 1997 J. Chem. Soc., Dalton Trans. 4289

34. Lobana T S, Sanchez A, Casas J, Garcia-Tasende M S and Sordo J S 1998 Inorg. Chim. Acta 267169

35. Lobana T S, Sanchez A, Casas J S, Castineiras A, Sordo J and Garcia-Tasende M S 1999 J. Chem. Soc., Dalton Trans. (submitted) 